\title{
Sleep Disturbance in Parkinson's Disease Varies with Age of Onset and Family History
}

\author{
Divya Madhusudhan', Daniella Sisniega', Andrew Ferree1, Janice Weinberg2, Marie Saint-Hilaire ${ }^{3}$, \\ Samuel Ellias ${ }^{3}$ Anna DePold Hohler ${ }^{3}$ \\ ${ }^{1}$ Boston University School of Medicine, Boston, USA \\ ${ }^{2}$ Boston University School of Public Health, Boston, USA \\ ${ }^{3}$ Department of Neurology, Boston University Medical Center, Boston, USA \\ Email: divyam18@bu.edu, danysis@bu.edu, andrew.ferree@gmail.com, janicew@bu.edu,neuromsh@bu.edu, sellias@bu.edu, \\ Anna.Hohler@bmc.org
}

How to cite this paper: Madhusudhan, D., Sisniega, D., Ferree, A., Weinberg, J., SaintHilaire, M., Ellias, S. and Hohler, A.D. (2016) Sleep Disturbance in Parkinson's Disease Varies with Age of Onset and Family History. Advances in Parkinson's Disease, 5, 107-113.

http://dx.doi.org/10.4236/apd.2016.54013

Received: October 21, 2016

Accepted: November 26, 2016

Published: November 30, 2016

Copyright $\odot 2016$ by authors and Scientific Research Publishing Inc. This work is licensed under the Creative Commons Attribution International License (CC BY 4.0).

http://creativecommons.org/licenses/by/4.0/

(c) (i) Open Access

\begin{abstract}
Introduction: Parkinson's disease (PD) is a progressive neurodegenerative disease more common in those over the age of 60 . PD is classically characterized by motor features, although patients may also experience non-motor symptoms. Sleep disturbances, such as rapid eye movement (REM) behavior disorder (RBD), are common in patients with PD and may precede onset of PD. Methods: Data was collected on patients with PD (358 subjects)in a movement disorders clinic at a safety net hospital. In this retrospective database analysis, the association of PD complications with age of onset was evaluated using chi-square tests and logistic regression. Results: Of the PD complications analyzed, there was a significant difference in sleep disturbances by age. Among the 358 PD patients, 120 individuals (33.5\%) had information regarding the presence or absence of sleep disturbances. There was a significant difference between the early (onset $<50)$ and later onset $(\geq 50)$ groups $(p=0.03)$ with the odds of having a sleep disorder for the early group 1.6 times that of the late group. Those subjects with siblings who also had PD had 2.0 times the odds of having a sleep disorder compared those without $(\mathrm{p}=0.02)$. Conclusion: Non-motor symptoms such as sleep disorders are a useful predictor of early onset PD. Genetic components of PD impact both motor and non-motor aspects of the disease.
\end{abstract}

\section{Keywords}

Parkinson's Disease (PD), Sleep Disorders, Rapid Eye Movement Behavior

Disorder (RBD), Age, Non-Motor Symptoms, Familial PD

\section{Introduction}

Parkinson's disease (PD) is a progressive neurodegenerative disease that manifests 
across a wide range of ages. PD is more common over the age of 60 , with a mean diagnosis age of 70.5 years, and is uncommon in people under 40 [1]. PD is classically characterized by four motor features: tremor, bradykinesia, rigidity, and gait instability. Although these motor features are primarily used to diagnose PD, patients are also affected by various non-motor symptoms.

Sleep disturbances are common in patients with $\mathrm{PD}$. There is a high prevalence of rapid eye movement (REM) behavior disorder (RBD) in PD and other synucleinopathies. RBD is characterized by loss of atonia during the REM cycle of sleep leading to enactment of dreams [2]. Approximately 50\% of patients with RBD develop parkinsonism within 10 years of RBD onset [3]; however, the variation of sleep disturbances with age of PD onset has not been extensively investigated. In addition, non-motor symptoms of PD are numerous and also include cognitive dysfunction and dementia, autonomic dysfunction, and mood disorders [4]. RBD may precede the diagnosis of an $\alpha$-synuclein disorder, such as PD, dementia with Lewy bodies, or multiple systems atrophy [5].

Genetics may likely influence age of PD onset and therefore may also correlate to PD complications that are associated with age of disease onset. To date, 15 genes and 20 genetic loci relating to parkinsonism have been identified [6]. PD caused by a single mutation in an inherited gene accounts for $3 \%-5 \%$ of sporadic and $30 \%$ of familial PD cases [7]. Examples of the numerous genes conferring PD risk and genes include parkin, SNCA, LRRK2, and PARK (at least 18 chromosomal regions related to PARK have been identified), which are associated with the clinical phenotype of PD symptoms [7] [8]. These genetic factors may influence the prevalence of PD complications such as sleep disturbances within families and could be important in understanding clinical subtypes of PD in patients.

In this study we are using a database to retrospectively assess the prevalence of sleep disorders in our PD population in relation to age of onset of the disease.

\section{Materials and Methods}

\subsection{Patient and Database}

A total of 358 PD subjects were entered into a Parkinson's Disease and Movement Disorders Database (PDMDD) in a tertiary care safety net hospital. The Institutional Review Board (IRB) reviewed and approved this study.

\subsection{Survey Content}

The surveys contained questions regarding family history, disease category, medications, and surgical history. The subject's primary language and insurance provider were reported. This information was self reported by patients. A racial category was chosen that best reflected their background, their education level was identified and an occupational background was indicated. The date of onset and the date of official diagnosis were listed. The date of onset was defined as the year in which any of the four classic motor symptoms of PD was first noted, by family members, a care provider, or the pa- 
tient. Any related diseases including dementia, various types of dystonia, and PD diagnosed in their parents, grandparents, and children were included. Data on PD complications, such as compulsive behaviors, dyskinesia, dementia, depression freezing, hallucinations, motor fluctuations, orthostatic hypotension, psychosis, or any autonomic dysfunction were also recorded in addition to sleep disturbances. This information was reported by physicians following the corresponding patients. Finally, any therapeutic surgical treatments the subject had undergone, as well as current and past use of medication were noted.

\subsection{Statistical Analysis}

All statistical analyses were performed using JMP Pro version 11.2. According to the American Parkinson Disease Association (APDA), though a majority of PD is diagnosed over age $60,10 \%-20 \%$ of PD patients are diagnosed before 50 . Therefore, the cohort was divided into two groups, early onset (under 50 years at age of onset) and late onset (50 years and over at age of onset) to ensure a truly younger onset population in the early onset group. Motor complications, family history, and treatment complications were indicated as dichotomous variables, classified as being either present or absent. The association of these categories with age of onset was analyzed using chisquare tests. The chi-square test was followed by a logistic regression model. Age of onset was analyzed against various PD complications to determine whether early or late onset PD was characterized by a particular PD complication. Confounding factors were defined as variables with $\mathrm{p}<0.1$ with chi-square analysis. Gender, race, and having a family member (father, mother, children) with PD were variables tested, and not found to be confounding factors.

\section{Results}

\subsection{Demographic Information}

The study population included 358 subjects with PD. The demographics of this cohort listed $56.5 \%$ of the population as male, and a majority of the study population was white at $83.0 \%$. The age of PD onset in the cohort ranged from age 27 to 86 with a mean age of onset of 58.4. The cohort was divided into early and late PD onset to determine whether specific PD complications were more characteristic of early or late disease onset; 79 subjects (22.1\%) were early onset 279 subjects $(77.9 \%)$ were late onset. There was a significant difference in the prevalence of sleep disturbances by age of onset, and thus the distribution of early and late onset by gender, sleep disturbances, and sibling history are shown in Table 1.

\subsection{Sleep Disturbances}

Among the 358 PD patients, 120 individuals had information regarding presence or absence of sleep disturbances. 17/33 (51.5\%) and 26/87 (29.9\%) of the early and late age of onset categories had sleep disturbances respectively. After performing a chi-squared test there was a significant difference between categories with respect to the odds of 
Table 1. Patient distribution of gender, sleep disturbances, and sibling history, and prevalence of various complications of $\mathrm{PD}$ by age of $\mathrm{PD}$ onset. $(\mathrm{W}=$ white, $\mathrm{NW}=$ non-white, $\mathrm{Y}=$ yes, $\mathrm{N}=$ no) ${ }^{*} \mathrm{p}<0.05$.

\begin{tabular}{|c|c|c|c|}
\hline & & Early PD Onset & Late PD Onset \\
\hline & Number & 79 & 279 \\
\hline & Gender (M:F) & $50: 28$ & $150: 126$ \\
\hline & Race (W:NW) & $68: 11$ & 229:50 \\
\hline & Any Family History of PD (Y:N) & $30: 50$ & $80: 199$ \\
\hline & Sleep disturbances & $17 / 33$ & $26 / 87$ \\
\hline & Sibling with PD & $8 / 79$ & $16 / 279$ \\
\hline & Sleep disorders* & 51.5 & 29.9 \\
\hline \multirow{4}{*}{$\begin{array}{l}\text { Complications } \\
\text { (\% Total) }\end{array}$} & Restless Leg Syndrome & 0 & 0.4 \\
\hline & Compulsive behavior & 8.9 & 6.1 \\
\hline & Hallucinations & 19.0 & 26.9 \\
\hline & Dementia & 12.7 & 22.6 \\
\hline
\end{tabular}

having a sleep disorder $(\mathrm{p}=0.03)$. Table 1 shows the prevalence of sleep disorders in early and late PD onset, along with the other non-motor complications that were investigated (restless leg syndrome, compulsive behavior, dementia, and hallucinations).

There was a significant difference between the early and late onset groups $(\mathrm{p}=0.03)$ with the odds of having a sleep disorder for the early group 1.6 times that of the late group (95\% CI: 1.3, 11.9). Furthermore, those subjects with siblings who also had PD had 2.0 times the odds of having a sleep disorder compared to those without $(\mathrm{p}=0.02$, 95\% CI: 1.1, 12.0). The prevalence of PD patients with sleep disorders among PD patients with or without family members with PD is shown in Table 2. Of the patients with a sibling with $\mathrm{PD}, 9 / 14$ (64.3\%) also had sleep disturbances and of patients without, 34/106 (32.1\%) had sleep disturbances. The distribution of patients with a sibling with PD by age of onset was 8/79 (10.1\%) and 16/279 (5.7\%) at early and late onset respectively.

\section{Discussion}

The cohort used in this study included a total of 358 subjects, primarily Caucasian, at a 1:1 male to female ratio, and of these patients, 120 had data on sleep disturbances. The major findings in this report include that there was a significantly higher incidence of sleep disturbances in early (onset $<50)$ compared to later onset $(\geq 50)$ in PD. Subjects with siblings with PD were more likely to have a sleep disorder than those without (Table 2). Other PD complications analyzed, including restless leg syndrome, hallucinations, and dementia did not vary in incidence between early and late onset PD (Table 2). Our finding that sleep disturbances are more common in early than late age onset has important implications in early PD diagnosis. RBD and other sleep disorders are being used as a predictor of PD, especially among early onset patients. Predicting PD 
Table 2. Prevalence of PD patients with sleep disorders among those who have family members with and without PD. ${ }^{*} \mathrm{p}<0.05$.

\begin{tabular}{ccccccccccc}
\hline & \multicolumn{8}{c}{ Family Member (\% total) } \\
\cline { 2 - 10 } & \multicolumn{2}{c}{ Father } & \multicolumn{2}{c}{ Mother } & \multicolumn{2}{c}{ Children } & \multicolumn{2}{c}{ Sibling* $^{*}$} \\
\cline { 2 - 10 } & With & Without & With & Without & With & Without & With & Without \\
\hline Sleep disorder & 36.3 & 35.7 & 66.7 & 33.3 & 33.3 & 35.9 & 64.2 & 32.1 \\
\hline
\end{tabular}

onset before motor symptoms manifest allows for improved neuroprotective treatment opportunities.

Several neurotransmitters are involved with sleep function. The serotonergic, dopaminergic, and cholinergic systems have all been implicated [9] [10] [11]. Studies have shown dopaminergic abnormalities are present in RBD prior to parkinsonism development [10]. By the time PD motor abnormalities are evident, 90\% of dopaminergic cells in the substantia nigra are dysfunctional [3]. Cholinergic nuclei in the basal forebrain, also involved in sleep regulation, are affected by Lewy body pathology [11] [12]. Using RBD as a predictor of PD before onset of motor symptoms may influence treatment options for patients.

$\mathrm{RBD}$ is more common in males and more strongly associated with the non-tremor subtype of PD and increased PD severity (higher Hoehn and Yahr stages) [3] [13]. While gender did not significantly affect whether or not PD patients had sleep disorders within our cohort, we did observe that the ratio of males to females with sleep disturbances was about 2:1. Studies have also shown that females have later age of onset [14], and their first symptoms are often tremor [15]. This information may provide physicians with predictors of which patients are prone to develop PD, and the clinical nature of their PD.

In addition to the association between age of $\mathrm{PD}$ onset and sleep disturbances, the data also showed that having a sibling (but not other relatives) with PD increased the likelihood that the patient would have sleep disturbances (Table 2). Gan-Or et al. showed that part of the genetic component affecting PD risk also affects RBD risk. Single nucleotide polymorphisms in various genes have been identified as PD markers and have been associated with RBD manifestation [16]. Further investigation is needed to determine how genetics influence the presence of sleep disorders in PD.

Non-motor symptoms such as sleep disorders are a useful predictor of early onset $\mathrm{PD}$, although one of the limitations of our study is that we do not know with which specific sleep disorders the PD patients presented. Sleep disorders such as RBD are often present before the motor symptoms of PD develop, and are being used as a diagnostic measure for PD. This appears true especially among early onset patients.

\section{Contributors and Acknowledgements}

Divya Madhusudhan contributed to the study design, statistical analysis, and manuscript writing and editing. Daniella Sisniega contributed to the study design, statistical analysis, and manuscript editing. Andrew Ferree contributed to the study design and 
manuscript editing. Janice Weinberg contributed to the statistical analysis and manuscript editing. Anna Hohler contributed to the study design, data collection, and manuscript editing.

Thank you to William Cavanaugh and Bobby McInnis for their assistance with and contribution to the PDMDD.

There were no sponsors for this research and there are no disclosures.

\section{Conflicts of Interest}

None.

\section{References}

[1] Van Den Eeden, S.K., Tanner, C.M., Bernstein, A.L., Fross, R.D., Leimpeter, A., Bloch, D.A. and Nelson, L.M. (2003) Incidence of Parkinson's Disease: Variation by Age, Gender, and Race/Ethnicity. American Journal of Epidemiology, 157, 1015-1022. https:/doi.org/10.1093/aje/kwg068

[2] Chaudhuri, K.R., Healy, D.G. and Schapira, A.H.V. (2006) Non-Motor Symptoms of Parkinson's Disease: Diagnosis and Management. The Lancet Neurology, 5, 235-245. https:/doi.org/10.1016/S1474-4422(06)70373-8

[3] Howell, M.J. and Schenck, C.H. (2015) Rapid Eye Movement Sleep Behavior Disorder and Neurodegenerative Disease. JAMA Neurology, 72, 707-712. https:/doi.org/10.1001/jamaneurol.2014.4563

[4] Hussl, A., Seppi, K. and Poewe, W. (2013) Nonmotor Symptoms in Parkinson's Disease. Expert Review of Neurotherapeutics, 13, 581. https:/doi.org/10.1586/ern.13.53

[5] Ondo, W.G. (2014) Sleep/Wake Problems in Parkinson's Disease: Pathophysiology and Clinicopathologic Correlations. Journal of Neural Transmission, 121, S3-S13.

[6] Yuan, L., Deng, X., Song, Z., Yang, Z., Ni, B., Chen, Y. and Deng, H. (2015) Genetic Analysis of the RAB39B Gene in Chinese Han Patients with Parkinson's Disease. Neurobiology of Aging, 36, 2907.e11-2907.e12. https:/doi.org/10.1016/j.neurobiolaging.2015.06.019

[7] Klein, C. and Westenberger, A. (2012) Genetics of Parkinson's Disease. Cold Spring Harbor Perspectives in Medicine, 2, a008888. https:/doi.org/10.1101/cshperspect.a008888

[8] Trinh, J., Vilarino-Guell, C. and Ross, O.A. (2015) A Commentary on Fine Mapping and Resequencing of the PARK16 Locus in Parkinson's Disease. Journal of Human Genetics, 60, 405-406. https:/doi.org/10.1038/jhg.2015.76

[9] Politis, M. and Niccolini, F. (2015) Serotonin in Parkinson's Disease. Behav. Brain Research, 277, 136-145. https:/doi.org/10.1016/j.bbr.2014.07.037

[10] Dhawan, V., Healy, D.G., Pal, S. and Chaudhuri, K.R. (2006) Sleep-Related Problems of Parkinson's Disease. Age and Ageing, 35, 220-228. https:/doi.org/10.1093/ageing/afj087

[11] Kotagal, V., Albin, R.L., Müller, M.L., Koeppe, R.A., Chervin, R.D., Frev, K.A. and Bohnen N.I. (2012) Symptoms of Rapid Eye Movement Sleep Behavior Disorder Are Associated with Cholinergic Denervation in Parkinson Disease. Annals of Neurology, 71, 560-568. https:/doi.org/10.1002/ana.22691

[12] Bohnen, N.I. and Albin, R.L. (2011) The Cholinergic System and Parkinson Disease. Behavioural Brain Research, 221, 564-573. https:/doi.org/10.1016/j.bbr.2009.12.048

[13] Boeve, B.F. (2009) REM Sleep Behavior Disorder: Updates Review of the Core Features, the REM Sleep Behavior Disorder-Neurodegenerative Disease Association, Evolving Concepts, Controversies, and Future Directions. Annals of the New York Academy of Sciences, 1184, 
15-54. https:/doi.org/10.1111/j.1749-6632.2009.05115.x

[14] Haaxma, C.A., Bloem, B.R., Borm, G.F., Oyen, W.J., Leenders, K.L., Eshuis, S., Booij, J., Dluzen, D.E. and Horstink, M.W. (2007) Gender Differences in Parkinson's Disease. Journal of Neurology, Neurosurgery, and Psychiatry, 78, 819-824.

https:/doi.org/10.1136/jnnp.2006.103788

[15] Solla, P., Cannas, A., Ibba, F.C., Loi, F., Corona, M., Orofino, G., Marrosu, M.G. and Marrosu, F. (2012) Gender Differences in Motor and Non-Motor Symptoms among Sardinian Patients with Parkinson's Disease. Journal of the Neurological Sciences, 323, 33-39. https:/doi.org/10.1016/j.jns.2012.07.026

[16] Gan-Or, Z., Girard, S.L., Noreau, A., Leblond, C.S., Gagnon, J.F., Arnulf, I., Mirarchi, C., Dauvilliers, Y., Desautels, A., Mitterling, T., Cochen De Cock, V., Frauscher, B., Monaca, C., Hogl, B., Dion, P.A., Postuma, R.B., Montplaisir, J.Y. and Rouleau, G.A. (2015) Parkinson's Disease Genetic Loci in Rapid Eye Movement Sleep Behavior Disorder. Journal of Molecular Neuroscience, 56, 617-622. https:/doi.org/10.1007/s12031-015-0569-7

Submit or recommend next manuscript to SCIRP and we will provide best service for you:

Accepting pre-submission inquiries through Email, Facebook, LinkedIn, Twitter, etc. A wide selection of journals (inclusive of 9 subjects, more than 200 journals)

Providing 24-hour high-quality service

User-friendly online submission system

Fair and swift peer-review system

Efficient typesetting and proofreading procedure

Display of the result of downloads and visits, as well as the number of cited articles Maximum dissemination of your research work

Submit your manuscript at: http://papersubmission.scirp.org/

Or contact apd@scirp.org 